\title{
The Quasi-static and Dynamic Mechanical Behavior of Epoxy Matrix Composites Reinforced with Curaua Fibers
}

\author{
Felipe do Carmo Amorim ${ }^{a, b}$, João Fellipe Brandão de Souza ${ }^{a}$, João Marciano Laredo dos Reis ${ }^{a}$ (D) \\ ${ }^{a}$ Laboratório de Mecânica Teórica e Aplicada, Programa de pós-graduação em Engenharia Mecânica, \\ Universidade Federal Fluminense, Rua Passo da Pátria 156, 24210-240, Niterói, RJ, Brasil \\ ${ }^{b}$ Departamento de Engenharia Mecânica, Centro Federal de Educação Tecnológica - CEFET-RJ, UnED \\ Itaguai, RJ, Brasil
}

Received: September 14, 2017; Revised: January 07, 2018; Accepted: February 09, 2018

\begin{abstract}
The research of natural fiber composites is growing due to the fact that the green materials combine low weight with good mechanical properties. Curaua fiber arises as a competitive natural fiber due to its abundance, low cost and a variety of applications. In this work, different weight fractions of Curaua fiber were used in order to obtain this natural composite material. Specimens of Curaua/Epoxy composites were tested in tensile and in flexion to observe the quasi-static mechanical properties and its physical properties due to temperature variation were evaluated by Dynamic Mechanical Analyses (DMA) analyses. An increase in fiber quantity showed an increase in both the modulus and the strength, leading to a stiff and less ductile material. The results also showed an increase in the viscoelastic stiffness of the epoxy matrix by the incorporation of Curaua fibers. The interaction between Curaua fibers and epoxy matrix affects segmental mobility of the epoxy chains.
\end{abstract}

Keywords: Natural Fibers, Mechanical Properties, Composite Materials.

\section{Introduction}

The applications of lignocellulosic fibers in reinforcement of composite structures are growing. Curaua fiber (Ananas erectifolius) is a Brazilian fiber development in the Amazon region (Para state) cultivated by small farmers. With an accelerated industrialization process the search for materials that can respond market needs is more often. Due to the fact that the industries are strongly competitive these new materials shall meet low cost, good mechanical and chemical properties.

Raw materials based on sustainability issues are a great solution for development of biocomposities considering the fact that they have an origin from renewable resources and ally some advantages such as biodegradability, high production and non-toxicity. Considering the properties of curaua, among natural fibers is the most competitive ${ }^{1}$. This fiber is replacing glass and carbon fiber in some applications. Green materials gain attention for several applications from aerospace to the building industry because it combines some special features like low weight and price with good physical properties ${ }^{1-5}$.

Automobile industries in a constant search of reduction of weight and $\mathrm{CO}_{2}$ emissions are making panels and others interior parts with natural fibers ${ }^{6,7}$.

Natural fiber polymer composites are materials that consist of a polymeric matrix with immersed fibers. The polymeric matrix can be in two types thermofixes and thermoplastics having the main function of ensuring the fiber integrity against chemical and environmental factors. The fibers, with over mechanical strength, endure the load. An important mechanical aspect of composites is the load transfer by the matrix to the fibers.

The reduction in interfacial mechanical properties between fiber and polymer matrix commonly decreases the fibers ability of to be a reinforcing component considering the hydrophilic character of lignocellulosic fibers.

Some disadvantages of Curaua, as all natural fiber, are related to the composition (cellulose, hemicellulose, lignin and waxes) and the elevated capacity of moisture absorption, which contribute to the poor adhesion between the polymeric matrix and fibers. The properties of natural fibers have a hard dependency of its chemical composition ${ }^{8-10}$. Good interfacial adhesion initially requires a good wetting between the fiber and the matrix, to achieve an extensive and proper interfacial contact. In order to improve the adhesion between Curaua/ Polypropylene, chemical treatment with $5 \mathrm{wt} \%$ aqueous $\mathrm{NaOH}$ solution for many hours at $23{ }^{\circ} \mathrm{C}$ is applied to the natural fibers ${ }^{10}$. Other treatment of natural fiber involves the exposure in hot water at $80^{\circ} \mathrm{C}$ for $1 \mathrm{~h}$ and then after both treatments dried in air for $48 \mathrm{~h}$. These procedures improve the mechanical interaction between hydrophobic epoxy resin and hydrophilic fibers, removing the waste components (lignin, hemicellulose) from the fibers ${ }^{11-14}$. 
The degradation of natural fiber is strongly connected with moisture and climatic conditions. Green fibers are mainly composed of sugar (cellulose and hemicellulose $)^{15}$. The chemical composition is distributed layer by layer and varies from fiber to fiber.

In this work, the mechanical properties, tensile and flexural properties of Curaua/Epoxy composites with different amount of Curaua fibers are investigated and also its viscoelastic behavior from very low temperatures, $-50^{\circ} \mathrm{C}$, to elevated ones, $180^{\circ} \mathrm{C}$. Viscoelastic behavior was evaluated by Dynamic Mechanical analysis and also the glass transition temperature.

\section{Materials and Methods}

\subsection{Materials}

To manufacture Curaua/Epoxy composites the natural fibers and polymer resin were manually mixed, poured in a $200 \mathrm{~mm}$ x $200 \mathrm{~mm}$ x $4 \mathrm{~mm}$ steel mold cured for one week at room temperature prior to testing. The composite resultant was post-cured for $8 \mathrm{~h}$ at $80^{\circ} \mathrm{C}$ in order to accelerate the curing process and improve some properties of composites. After the curing process, specimens were cutted according the specific standards.

The epoxy resin used in this work was provided by Epoxyfiber $^{\circledR}$. Based on diglycidyl ether of bisphenol A and an aliphatic amine hardener. The epoxy resin has low viscosity and the mix ratio to hardener of $4: 1$. Resin properties by the manufactures are shown in Table 1.

Table 1. Properties of Epoxy resin at room temperature.

\begin{tabular}{lc}
\hline Property & Epoxy \\
\hline Viscosity at $25^{\circ} \mathrm{C} \mu$ (mPa.s) & $12000-13000$ \\
Density $\rho\left(\mathrm{g} / \mathrm{cm}^{3}\right)$ & 1.16 \\
Heat Distortion Temperature HDT $\left({ }^{\circ} \mathrm{C}\right)$ & 100 \\
Modulus of Elasticity E (GPa) & 5.0 \\
Flexural Strength (MPa) (ASTM D790) & 60 \\
Tensile Strength (MPa) (ASTM D638) & 73 \\
Maximum Elongation (\%) & 4 \\
\hline
\end{tabular}

Curaua fiber (Ananas erectifolius) from Para state is a type of lignocellulosic fiber. The fiber has a diameter of 50 $\mu \mathrm{m}$, a length of $6 \mathrm{~mm}$ and the aspect ratio (L/D) is 120 . The Curaua fibers are shown in Figure 1.

Curaua fibers were manually sifted, rinsed with water and dried in an electric oven. There was not any kind of pre-treatment on the fibers, they were used as it was collected from the nature. The fibers were chopped and blended with the polymer epoxy resin by $30 \%, 40 \%$ and $50 \%$ of the total weight.

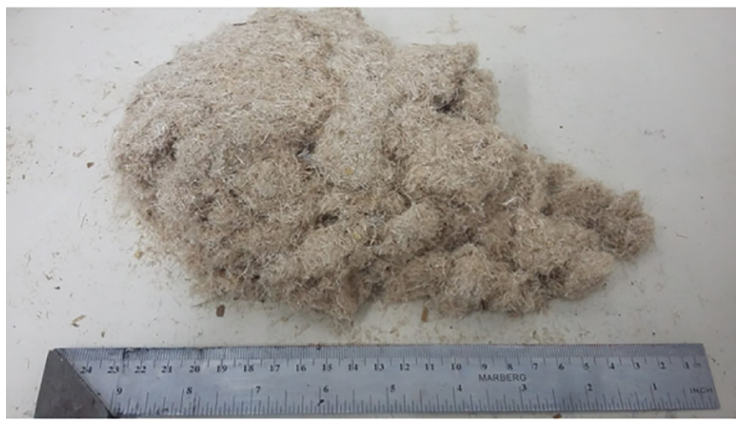

Figure 1. Curaua fibers.

\subsection{Methods}

Mechanical tensile and flexural tests at different weight $\%$ were performed by Shimadzu ${ }^{\circledR}$ AG-X universal testing machine according to ASTM D3039/D3039M-14 ${ }^{16}$ and ASTM D790-10 ${ }^{17}$, respectively. The tensile tests were performed with a cross-head speed of $2 \mathrm{~mm} / \mathrm{min}$ and the three-point bending with a speed of $1.5 \mathrm{~mm} / \mathrm{min}$. Four specimens were tested for each type of mechanical testing. Figure 2 shows the tensile and three-point bending set-up for Curaua/Epoxy tests.

The dynamic mechanical analysis (DMA) was used for measuring the temperature influence in elastic properties of all formulations of natural fiber composite. Tests were performed with three-point bending configuration and the span of the supports was $40 \mathrm{~mm}$, according to ASTM $\mathrm{D} 7028^{18}$. The samples were scanned from $-50^{\circ} \mathrm{C}$ to $180^{\circ} \mathrm{C}$ with a heating rate of $2^{\circ} \mathrm{C} / \mathrm{min}$ at $0.01,0.1,1,10$ and $100 \mathrm{~Hz}$.

\section{Results and Discussion}

\subsection{Tensile and Flexural Experiments}

The tensile and three-point bending test results of composite manufactured with different content of Curaua fibers are presented in Table 2.

From table 2 it can be seen the tensile and flexural maximum strength and stiffness are dependent of fiber quantity. As fiber content increases the tensile and flexural modulus increase improving stiffness. Although the fibers improve the strength of the studied composite, with the addition of fiber the tensile and flexural strength decrease compared to the epoxy matrix. Increasing the quantity of Curaua fiber from $30 \%$ to $40 \%$, an increase of $28.5 \%$ in the tensile strength is calculated and $50 \%$ higher tensile strength is reported for composites manufactured with $50 \%$ of Curaua fibers. Stiffness, as previously mentioned, increased overall, is elevated $31.2 \%$ when $30 \%$ of Curaua fibers are used to produce this natural fiber composite and an elevation of $99.4 \%$ and $145 \%$ is calculated when $40 \%$ and $50 \%$ of Curaua fibers are used. Similar behavior is observed when Curaua/Epoxy 


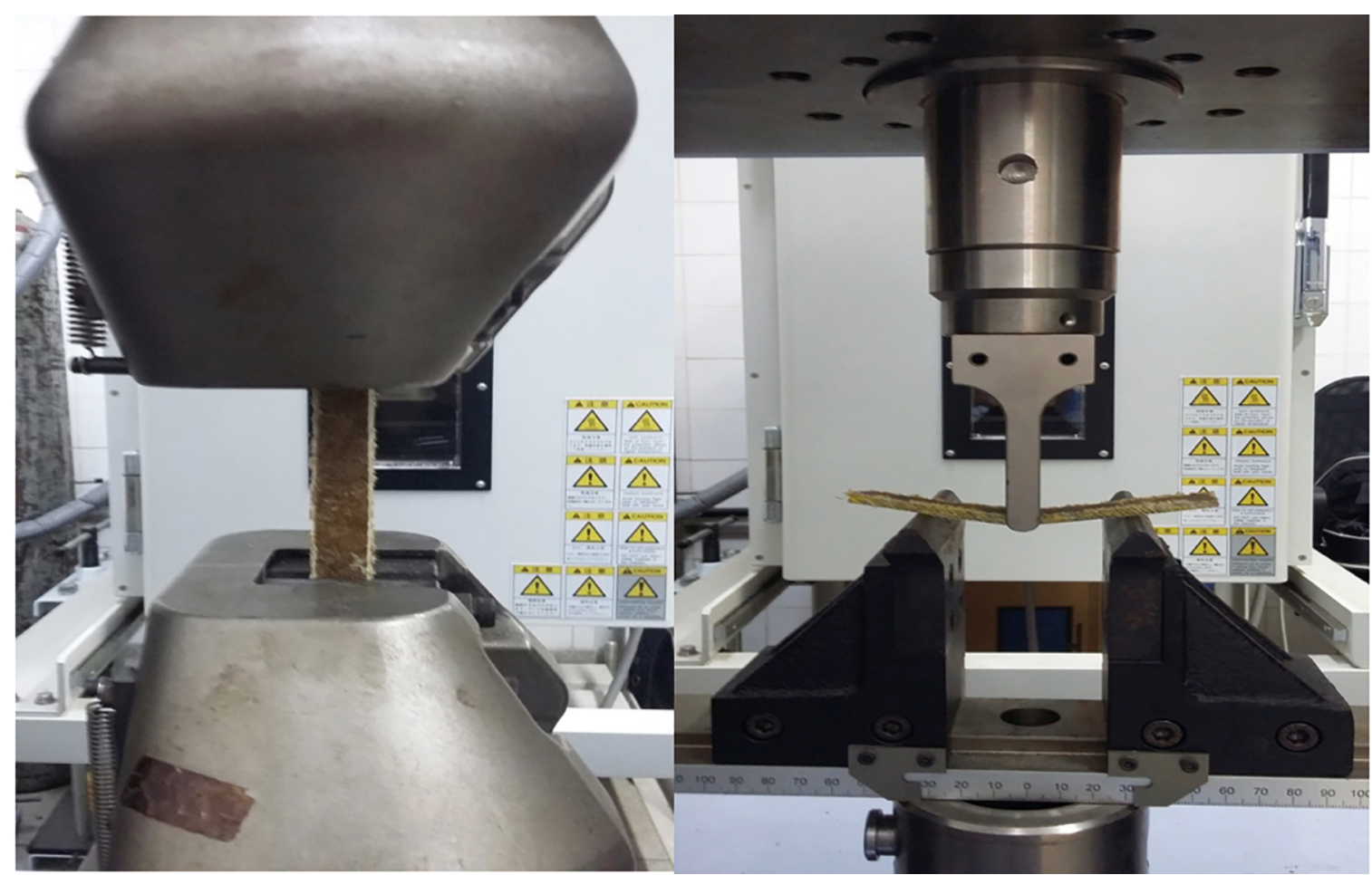

Figure 2. Tensile and flexural test set-up

Table 2. Tensile and three-point bending test results of Curaua fibers composite

\begin{tabular}{ccccc}
\hline Fiber content (\%) & $\begin{array}{c}\text { Maximum Tensile } \\
\text { Strength }(\mathrm{MPa})\end{array}$ & $\begin{array}{c}\text { Modulus of Elasticity } \\
(\mathrm{GPa})\end{array}$ & $\begin{array}{c}\text { Maximum Flexural } \\
\text { Strength (MPa) }\end{array}$ & Flexural Modulus (GPa) \\
\hline 0 & 53.84 & 1.73 & 85.39 & 2.71 \\
30 & 20.20 & 2.27 & 52.02 & 2.94 \\
40 & 25.95 & 3.45 & 59.00 & 4.06 \\
50 & 30.29 & 4.24 & 67.45 & 4.37 \\
\hline
\end{tabular}

composites are evaluated in flexion. Elevating the quantity of Curaua fiber from $30 \%$ to $40 \%$ at $13.4 \%$ improve on the flexural strength is observed and $29.7 \%$ higher values of flexural strength is calculated when $50 \%$ of Curaua fibers is used as matrix reinforcement. Again, the flexural stiffness increased in all composite configurations tested. Using 30\% of Curaua fibers, stiffness increased $8.5 \%$. Higher values, $49.8 \%$ and $61.3 \%$, are calculated when the content of Curaua fibers is elevated to $40 \%$ and $50 \%$, respectively. These results show that Curaua fibers can be an attractive natural fiber to be used as reinforcement due to its high specific strength and stiffness.

Figure 3 shows the typical tensile stress vs. strain curves for Curaua/Epoxy composites with 0,30, 40 and 50\% of fiber.

Figure 3 shows that Curaua fiber hardly influences the tensile behavior of Curaua fiber composites. Despite the decrease in the maximum tensile strength when Curaua fibers are introduced in the epoxy matrix, it can be seen a significant increase in the stress vs. strain slope representing a higher stiffness for higher values of Curaua fiber content.

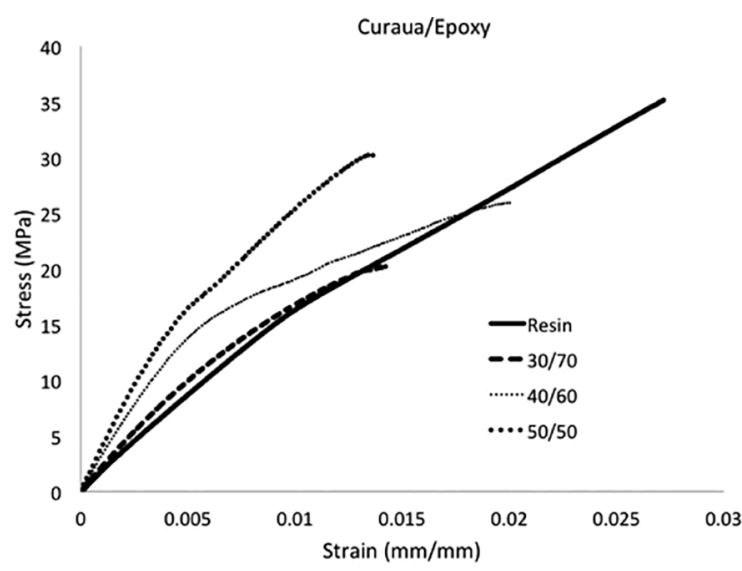

Figure 3. Typical tensile stress vs. strain curves of Curaua/Epoxy composites.

Both modulus of elasticity and maximum strength are fiber-dependent. The stress-strain curve becomes nonlinear for all Curaua fiber composites. This nonlinear behavior can be explained considering that short shredded Curaua fibers 
results in limited interaction between fibers and matrix, the presence of extensive voids and poor bonding; this reduces the effect of fiber reinforcement in the composite ${ }^{19}$. Further improve on the fiber surface preparation should be performed in the future.

Figure 4 displays the three-point bending stress vs. strain curves for Curaua/Epoxy composite with 0, 30, 40 and $50 \%$ of Curaua fiber.

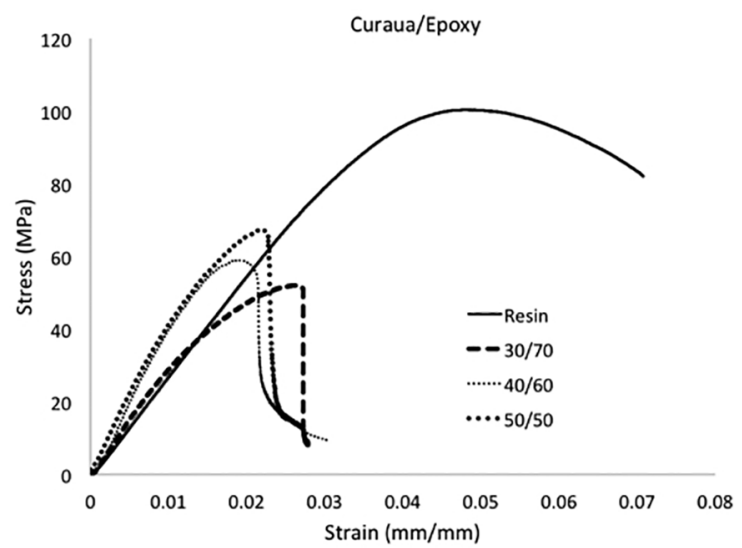

Figure 4. Typical flexural stress vs. strain curves of Curaua/Epoxy composites.

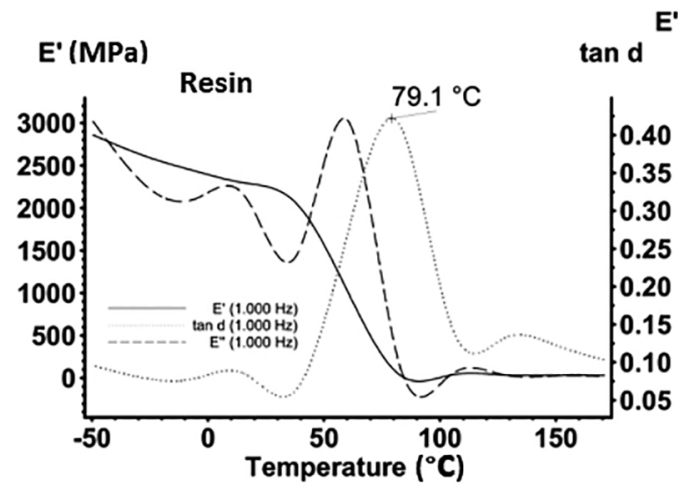

E"(MPa)


"(MPa)


$\mathrm{E}^{\prime \prime}(\mathrm{MPa})$ unreinforced epoxy matrix. The degree of fiber adhesion affects the mobility of the epoxy molecular chains and hence its temperature transition to an amorphous structure. It can be seen from the peak of $\tan \delta$ that as Curaua fibers are introduced in the epoxy polymer matrix, the glass transition temperature

The curves showed in figure 4 present the strong influence of quantity of fiber with modification in stiffness and strength of composite. Accordingly to what is observed in tension, when Curaua fibers are inserted in the epoxy matrix the composite has lower deflection and therefore fails for lower strain. Despite that, it can be seen a significant improvement in bending stiffness. This can be observed by the increase in the angle of the bending stress vs. strain slope. Increasing Curaua fiber content bending stress also increases, but strain at failure is around the same range.

\subsection{Thermal Analysis of Curaua/Epoxy Composites by DMA}

The DMA results of $1 \mathrm{~Hz}$ analysis are presented in figure 5. The specimens were tested from $-50^{\circ} \mathrm{C}$ to $180^{\circ} \mathrm{C}$.

Figure 5 presents complete sets of DMA curves (E', E" and $\tan \delta$ ) for the pure epoxy and Curaua/Epoxy composite specimens. It can be seen an increase in the dynamic bending properties of Curaua/Epoxy composites when compared to

Figure 5. DMA test results of Curaua/Epoxy composites at $1 \mathrm{~Hz}$ 
also increases. It should be noticed that all composite loss modulus ( $\left.E^{\prime \prime}\right)$ peaks are displaced higher temperatures in comparison to the pure epoxy peak, indicating a reduction in the chain flexibility. A low interfacial strength will not allow the chains to move without much restriction at the contact with the Curaua fibers. Table 3 shows the storage modulus (E'), Tan Delta and glass transition temperature (Tg) of composite Curaua/Epoxy with different content of fiber.

From table 3 it can be seen that the increase in Curaua fiber quantity improves the $\mathrm{Tg}$ of the composite and also improves the storage modulus. The decrease in the $\tan \delta$ values indicates a reduction in the epoxy chain mobility.

Figure 6 shows the viscoelastic behavior of composite material when it exhibits a dependency of test frequency.

Figure 6 shows a strong dependency of Curaua/Epoxy composites from test frequencies revealing the viscoelastic
Table 3. DMA test results of Curaua fiber composites.

\begin{tabular}{lcccc}
\hline \multirow{2}{*}{ Property } & \multicolumn{4}{c}{ Fiber quantity (\%) } \\
\cline { 2 - 5 } & 0 & $30 \%$ & $40 \%$ & $50 \%$ \\
\hline $\mathrm{E}^{\prime}(\mathrm{GPa})$ & 2.20 & 4.89 & 3.89 & 3.29 \\
$\tan \delta$ & 0.422 & 0.276 & 0.245 & 0.269 \\
$\mathrm{Tg}\left({ }^{\circ} \mathrm{C}\right)$ & 79.1 & 85.6 & 93.2 & 94.9 \\
\hline
\end{tabular}

property is these composites. For all tested composites, as test frequency increases, the storage modulus also increases. This means that the Curaua fibers increase the epoxy matrix capacity to support mechanical constraints with recoverable viscoelastic deformation. In particular the composite stiffness is substantially increased with Curaua fiber incorporation, which is also comparable to a result found in quasi-static tensile and flexural tests.
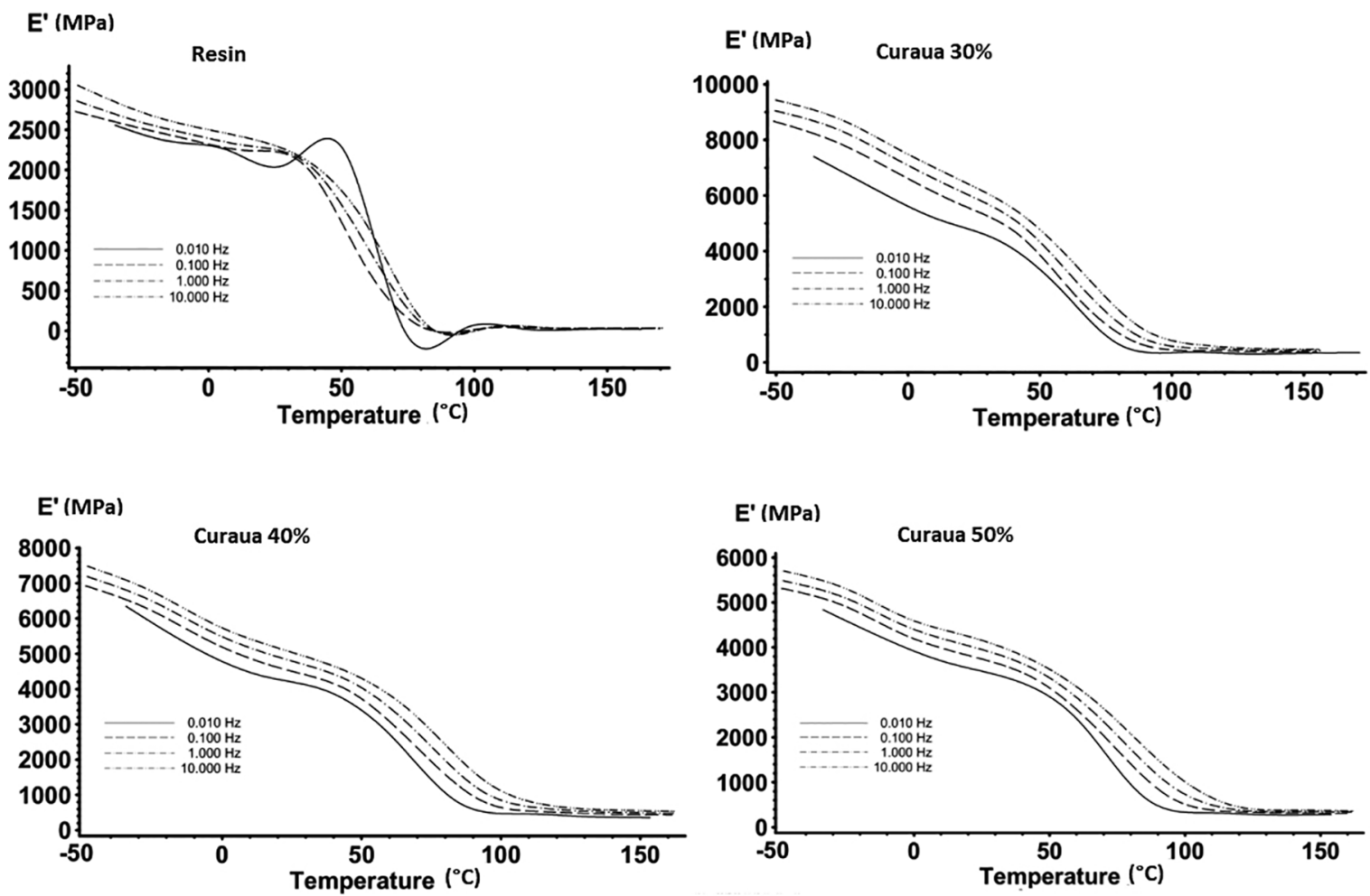

Figure 6. Curaua/Epoxy composites storage modulus ( $\left.\mathrm{E}^{\prime}\right)$ at different frequencies. 


\section{Conclusions}

In this research, different mechanical and dynamic characterizations of a natural fiber composite manufactured with Curaua fibers are presented, directed toward the exploration of possible composite materials for structural and non-structural applications. It is shown by the mechanical test results that despite the decrease in tensile and flexural strength when compared to pure epoxy, incorporating Curaua fibers higher stiffness in both tensile and flexural behavior is observed. Higher values are reported for higher fiber quantities. The glass transition temperature assessed by DMA analysis displayed that the results have a strong relation with rigidity of the chemical structure of the matrix. Extreme temperatures $-50^{\circ} \mathrm{C}$ to $180^{\circ} \mathrm{C}$ were used to evaluate stiffness and phase change of the composite. Also, increasing Curaua fiber content, it is observed an elevation in the glass transition temperature. The composite material exhibited the viscoelastic behavior showing the dependency of test rate. The elastic characteristics related to storage modulus (E') are more evident at higher frequencies. These results show that Curaua/Epoxy composites have a potential to be used instead of conventional synthetic composites in engineering applications where low weight, easily recyclable and environmental friendly materials are desirable.

\section{Acknowledgments}

The authors would like to thank the United States Air Force (through the SOARD grant FA9550-16-1-0482).

\section{References}

1. Spinacé MAS, Lambert CS, Fermoselli KKG, De Paoli MA. Characterization of lignocellulosic curaua fibres. Carbohydrate Polymers. 2009;77(1):47-53.

2. Bispo SJL, Freire Junior RCS, de Aquino EMF. Mechanical Properties Analysis of Polypropylene Biocomposites Reinforced with Curaua Fiber. Materials Research. 2015;18(4):833-837.

3. Hosokawa MN, Darros AB, Moris VAS, Paiva JMF. Polyhydroxybutyrate Composites with Random Mats of Sisal and Coconut Fibers. Materials Research. 2017;20(1):279-290.

4. Morais JA, Gadioli R, De Paoli MA. Curaua fiber reinforced high-density polyethylene composites: effect of impact modifier and fiber loading. Polímeros. 2016:26(2):115-122.

5. Corrêa AC, Teixeira EM, Pessan LA, Mattoso LHC. Cellulose nanofibers from curaua fibers. Cellulose. 2010;17(6):1183-1192.

6. Holbery J, Houston D. Natural-fiber-reinforced polymer composites in automotive applications. JOM. 2006;58(11):80-86.
7. Joshi SV, Drzal LT, Mohanty AK, Arora S. Are natural fiber composites environmentally superior to glass fiber reinforced composites? Composites Part A: Applied Science and Manufacturing. 2004;35(3):371-376.

8. Mohammed L, Ansari MNM, Pua G, Jawaid M, Saiful Islam M. A review on Natural Fiber Reinforced Polymer Composites and Its Applications. International Journal of Polymer Science. 2015;2015:243947.

9. Sain M, Panthapulakkal S. Green fibre thermoplastic composites. In: Baillie C, ed. Green Composites - Polymer composites and the environment. Oxford: Woodhead Publishing; 2004. p. 181206.

10. Spinacé MAS, Fermoseli KKG, De Paoli MA. Recycled polypropylene reinforced with curaua fibers by extrusion. Journal of Applied Polymer Science. 2009;112(6):3686-3694.

11. Almeida Júnior JHS, Amico SC, Botelho EC, Amado FDR. Hybridization effect on the mechanical properties of curaua/ glass fiber composites. Composites Part B: Engineering. 2013;55:492-497.

12. Cardoso PHM, Bastian FL, Thiré RMSM. Curaua Fibers/ Epoxy Laminates with improved Mechanical Properties: Effects of Fiber Treatment Conditions. Macromolecular Symposia. 2014;344(1):63-70.

13. Gomes A, Matsuo T, Goda K, Ohgi J. Development and effect of alkali treatment on tensile properties of curaua fiber green composites. Composites Part A: Applied Science and Manufacturing. 2007;38(8):1811-1820.

14. Leão RM, Luz SM, Araujo JA, Novack K. Surface Treatment of Coconut Fiber and its Application in Composite Materials for Reinforcement of Polypropylene. Journal of Natural Fibers. 2015;12(6):574-586.

15. Faruk O, Bledzki AK, Fink HP, Sain M. Biocomposites reinforced with natural fibers: 2000-2010. Progress in Polymer Science. 2012;37(11):1552-1596.

16. ASTM International. ASTM D3039/D3039M-14 - Standard Test method for Tensile Properties of Polymer Matrix Composite Materials. West Conshohocken: ASTM International; 2014.

17. ASTM International. ASTM D790-10 - Standard Test Methods for Flexural Properties of Unreinforced and Reinforced Plastics and Electrical Insulating Material. West Conshohocken: ASTM International; 2010.

18. ASTM International. ASTM D7028-07 - Standard Test Method for Glass Transition Temperature (DMA T) of Polymer Matrix Composites by Dynamic Mechanical Analysis (DMA). West Conshohocken: ASTM International; 2007.

19. Tran LQN, Yuan XW, Bhattacharyya D, Fuentes C, Van Vuure AW, Verpoest I. Fiber-matrix interfacial adhesion in natural fiber composites. International Journal of Modern Physics B. 2015;29:1540018. 